\title{
ANALISIS PEWARNA RHODAMIN B DALAM SAUS TOMAT YANG BEREDAR DI KOTA MAKASSAR SECARA SPEKTROFOTOMETRI UV-VIS
}

\author{
St. Maryam, A. Muflihunna, Ulfa Sajadah \\ Fakultas Farmasi Universitas Muslim Indonesia Makassar \\ Email : st.maryam_apt@yahoo.com
}

\begin{abstract}
Analysis of Rhodamin B dye have done in several tomato sauce produced of Makassar city. The research aims to define and analyze levels of compound Rhodamin B in tomato sauce produced Makassar which is source from the sidewalk traders, and industries households by Thin Layer Chromatography (TLC) method for qualitative analysis and spectrophotometry UV-Vis for quantitative analysis. This research can provide benefits to the public about dangers of consuming food that contain of Rhodamin B dye. Extraction with wool yarn, identified by TLC, and analysis by spectrophotometry UV Vis were covered in this study. Research results showed that the four of tomato sauce produced in makassar city did not contain of Rhodamin $B$ dye and that product can be used by the citizen.
\end{abstract}

Key Words : Rhodamin B, Spectrophotometry UV-Vis, Tomato Sauce.

\section{PENDAHULUAN}

Saat ini begitu banyak terjadi perkembangan di bidang industri makanan dan minuman yang bertujuan untuk menarik perhatian para konsumen. Oleh karena itu, produsen makanan dan minuman menambahkan zat tambahan makanan atau yang sering disebut sebagai food additive dalam produknya, diantaranya zat pewarna, pemanis, penyedap rasa dan aroma, pengawet, dan lain-lain (Suparapti, 2000).

Beberapa zat pewarna sintesis ada yang membahayakan kesehatan sehingga tidak

diijinkan penggunaannya. Beberapa produsen makanan dan minuman masih menggunakan zat pewarna sintesis yang dilarang tersebut untuk produknya dengan alasan zat warna tersebut memiliki warna yang cerah, praktis digunakan, harganya relatif murah, serta tersedia dalam kemasan kecil dipasaran sehingga memungkinkan masyarakat tingkat bawah untuk membelinya (Suparapti, 2000).

Pemerintah Indonesia melalui Peraturan Menteri Kseshatan (Permenkes) No. 239 /Menkes/ Per/ V/85 menetapkan 30 zat pewarna 
Analisis Pewarna Rhodamin B Dalam Saus Tomat Yang Beredar Di Kota Makassar Secara Spektrofotometri UV-VIS

berbahaya. Rhodamin B termasuk salah satu zat pewarna yang dinyatakan sebagai zat pewarna berbahaya dan dilarang digunakan pada produk pangan. Zat warna Rhodamin B walaupun telah dilarang penggunaannya ternyata masih ada produsen yang sengaja menambahkan zat warna Rhodamin B untuk produk cabe giling dan saos sebagai pewarna merah dengan alasan warnanya sangat bagus, mudah didapat, dan murah harganya. Sebagian produk tersebut tidak mencantumkan kode, label, merek, jenis, atau data lainnya yang berhubungan dengan zat warna tersebut (Syah et al., 2005). Rhodamin B merupakan pewarna yang bersifat racun dan dapat menyebabkan kanker. Kelebihan dosis bahan ini dapat menyebabkan keracunan berbahaya jika tertelan, terhirup, atau terserap melalui kulit (Trestiati, 2003).

Menyadari bahaya yang ditimbulkan oleh penggunaan pewarna Rhodamin B pada pangan, maka dilakukan penelitian mengenai identifikasi pewarna Rhodamin B dalam saus tomat yang beredar di Makassar.

\section{METODE PENELITIAN}

\section{Alat dan Bahan}

Adapun alat yang digunakan adalah Gelas ukur (Pyrex), gelas piala
(Pyrex), kompor listrik, labu takar (Pyrex), pipa kapiler, pipet volume (Pyrex), serangkaian alat kromatografi lapis tipis, spketrofotometer Uv-vis (Shimadzu), dan timbangan analitik (Sartorius).

Bahan yang dipakai adalah Air suling, Amonia p.a (E.Merk), benang wol, etanol p.a (E.Merk), etil asetat, $\mathrm{HCl} 4 \mathrm{M}$, metanol p.a (E.Merk), Rhodamin p.a (E.Merk),dan saus tomat yang diperoleh dari pedagang di Makassar.

\section{Prosedur Penelitian}

\section{Analisis kualitatif dengan KLT}

\section{Pembuatan larutan uji (A)}

Sampel saus tomat ditimbang sebanyak 5 gram, ditambahkan 4 tetes $\mathrm{HCl} 4 \mathrm{M}$ dan 5-10 $\mathrm{mL}$ metanol. Dipananskan di atas penangas air \pm 5 menit, disaring dengan kertas saring yang berisi natrium sulfat anhidrat. Diambil filtrat dan dimasukkan ke dalam botol vial $5 \mathrm{~mL}$.

\section{Pembuatan larutan baku (B)}

Ditimbang sebanyak $\pm 5 \mathrm{mg}$ pewarna Rhodamin B baku (pembanding), dilarutkan dalam $10 \mathrm{~mL}$ metaniol, dikocok hingga larut.

\section{Uji Identifikasi sampel}

Disiapkan plat $\mathrm{KLT}$, dilakukan penotolan larutan A dan B secara terpisah, kemudian dimasukkan ke dalam chamber yang telah dijenuhkan 
Analisis Pewarna Rhodamin B Dalam Saus Tomat Yang Beredar Di Kota Makassar Secara Spektrofotometri UV-VIS

dengan etil asetat: metanol: amonia (75:30:15). Setelah proses elusi selesai, amati noda dibawah UV 254 $\mathrm{nm}$, noda merah berfluoresensi kuning menunjukkan adanya Rhodamin B.

\section{Analisis kuantitatif dengan spektrofotometri UV-Vis}

\section{Pembuatan larutan uji}

Sampel saus tomat sebanyak 5 gram ditambahkan $100 \mathrm{~mL}$ larutan amonia $2 \%$ dalam etanol $70 \%$ dan diidiamkan selama semalam hingga semua pewarna larut. Larutan disaring menggunakan kertas Whatman, kemudian diuapkan selama 4 jam pada suhu $65^{\circ} \mathrm{C}$. sampel yang tel;ah pekat dilarutkan dalam $30 \mathrm{~mL}$ aquadest, kemudian dimasukkan ke dalam corong pisah $250 \mathrm{~mL}$, lalu ditambahkan $6 \mathrm{~mL}$ larutan natrium hidroksida $10 \%$ dan dikocok. Larutan diekstraksi dengan $30 \mathrm{~mL}$ dietil eter kemudian dikocok dan didiamkan hingga larutan membentuk 2 lapisan yaitu lapisan eter jernih (atas) dan lapisan air berwarna merah (bawah). Lapisan air dikeluarkan, hingga hanya terdapat lapisan eter kemudian dicuci dengan $\mathrm{NaOH} 0,5 \%$ sebanyak $5 \mathrm{~mL}$ dengan cara dikocok kemudian didiamkan. Dari pencucian tersebut maka akan terbentuk 2 lapisan lagi yaitu lapisan eter jernih (atas) dan lapisan air berwarna kecoklatan (bawah). Lapisan air dibagian bawah dikeluarkan hingga hanya terdapat ekstrak eter yang kemudian diekstraksi 3 kali, tiap kali dengan $10 \mathrm{~mL}$ asam klorida $0,1 \mathrm{~N}$ hingga lapisan eter tidak berwarna lagi. Lapisan eter dibuang, ekstrak asam klorida ditampung dalam labu tentuukur $50 \mathrm{~mL}$.

\section{Pembuatan larutan baku}

Ditimbang sebanyak $0,1 \mathrm{~g}$ Rhodamin B, kemudian dimasukkan ke dalam labu ukur $100 \mathrm{~mL}$ dan ditambahkan $\mathrm{HCl} \quad 0,1 \mathrm{~N}$, sehingga diperoleh dengan konsentrasi 1000 ppm. Kemudian diencerkan larutan Rhodamin B tersebut hingga diperoleh konsentrasi 1, 2, 3, 4, 5 ppm. Kemudian dilakukan pengukuran pada panjang gelombang maksimum 538 $\mathrm{nm}$.

\section{HASIL PENELITIAN}

\section{Identifikasi secara KLT}

Tabel 1. Hasil identifikasi Rhodamin B dalam saus tomat secara KLT dengan cairan peneglusi etl asetat : metanol : amonia $(37: 15: 7,5)$.

\begin{tabular}{ccccc}
\hline Kode Sampel & Parameter/ Hasil KLT & UV 254/366 nm & Jarak Noda (cm) & Nilai Rf \\
\hline A & Tidak ada noda & Tidak berfluoresensi & - & - \\
\hline B & Noda 1 : Kuning & \multirow{2}{*}{ Tidak berfluoresensi } & 7,5 & 0,625 \\
& Noda 2 : Merah & Tidak berfluoresensi & 7,8 & 0,4 \\
\hline C & Noda 1 : Kuning & T,5 & 0,625 \\
\hline
\end{tabular}


Analisis Pewarna Rhodamin B Dalam Saus Tomat Yang Beredar Di Kota Makassar Secara Spektrofotometri UV-VIS

\begin{tabular}{|c|c|c|c|c|}
\hline & $\begin{array}{l}\text { Noda } 2: \text { Merah } \\
\text { Noda } 3: \text { Merah }\end{array}$ & & $\begin{array}{l}5,9 \\
4,8 \\
\end{array}$ & $\begin{array}{c}0,491 \\
0,4\end{array}$ \\
\hline D & $\begin{array}{l}\text { Noda } 1: \text { Kuning } \\
\text { Noda } 2: \text { Merah } \\
\text { Noda } 3: \text { Merah }\end{array}$ & Tidak berfluoresensi & $\begin{array}{l}7,5 \\
5,9 \\
4,8\end{array}$ & $\begin{array}{c}0,625 \\
0,491 \\
0,4\end{array}$ \\
\hline $\begin{array}{c}\text { Baku pembanding } \\
\text { (Rhodamin B) }\end{array}$ & Merah terang & $\begin{array}{l}\text { Berfluoresensi } \\
\text { orange }\end{array}$ & 8,5 & 0,708 \\
\hline
\end{tabular}

\section{Identifikasi secara spektrofotometri UV-Vis}

Tabel 2. Hasil pengukuran serapan larutan Rhodamin B murni

\begin{tabular}{cc}
\hline Konsentrasi (ppm) & Absorban (B) \\
\hline 0 & 0,0725 \\
\hline 1 & 0,2317 \\
\hline 2 & 0,3812 \\
\hline 3 & 0,5941 \\
\hline 5 & 0,7285 \\
\hline
\end{tabular}

Tabel 3. Hasil identifikasi sampel saus tomat

\begin{tabular}{ccc}
\hline Kode saus tomat & Berat sampel (gram) & Absorban (A) \\
\hline A & 5,18 & 0,0723 \\
B & 5,20 & 0,0724 \\
C & 5,20 & 0,0724 \\
D & 5,18 & 0,0722 \\
\hline
\end{tabular}

\section{PEMBAHASAN}

Penelitian ini dilakukan untuk mengetahui ada tidaknya pewarna Rhodamin B pada beberapa sampel saus tomat dan berapa banyak kadar pewarna tersebut yang terkamdung dalam saus tomat yang beredar di kota Makassar, yang dianalisis dengan dua metode yaitu secara kromatografi Lapis Tipis dan sepktrofotometri UVVis. Identifikasi secara kromatografi lapis tipis pertama-tama sampel diisolasi dengan benang wol terlebih dahulu, dengan maksud agar zat-zat lain yang terkandung didalam saus tomat itu tidak sepenuhnya terikut saat diuji pada $\mathrm{kLT}$ nanti, dengan bantuan asam klorida agar zat warna yang diinginkan terikat pada benang wol, kemudian didihkan dengan tujuan agar zat warna terserap secara sempurna pada benang wol, kemudian benang wol dibasakan dengan tujuan untuk melepaskan zat warna yang telah terikat. Hasil KLT menunjukkan bahwa zat pewarna Rhodamin B adalah bentuk tunggal berwarna merah keunguan.

Semua sampel yang telah diuji kualitatif dengan melihat persamaan warna dan nilai Rf nya menunjukkan bahwa dari sampel saus tomat yang 

Spektrofotometri UV-VIS

diujikan, tidak ada yang mengandung

zat pewarna bahaya Rhodamin $\mathrm{B}$. namun untuk lebih meyakinkan lagi apakah betul saus tomat tersebut tidak mengandung Rhodamin B, maka selanjutnya dilakukan analisis dengan spektrofotometer UV-Vis, dimana metode ini lebih dikhususkan pada perhitungan kadar dari suatu zat tertentu yang terkandung dalam sampel tersebut. Hasil secara spektrofotometer menunjukkan bahwa sampel tersebut tidak mengandung zat pewarna Rhodamin B dimana nilai absorbansinya nol, dengan larutan yang tidak berwarna atau bening.

\section{KESIMPULAN}

Berdasarkan hasil penelitian yang telah dilakukan, maka dapat disimpulkan bahwa saus tomat yang beredar di kota Makassar, khususnya produksi kota Makassar tidak mengandung pewarna bahaya Rhodamin B dan aman untuk dikonsumsi.

\section{DAFTAR PUSTAKA}

Depkes RI, 2000, Metode Analisis PPOMN, Pusat Pengujian Obat dan Makanan, Badan POM RI, Jakarta.
Djalil, 2005, Identifikasi Zat Warna Kuning Metanil (Metanil Yellow) dengan Metode Kromatografi Lapis Tipis (KLT), Fakultas Farmasi UMP, Purwokwerto.

Depkes RI, 1995, Farmakope Indonesia, Edisi IV, Ditejen POM, Jakarta.

Gritter, R.J., 1991, Pengantar Kimia, Penerbit ITB, Bandung.

Mulja, M. dan Syahrani, A., 1990, Aplikasi Analisis Spektrofotometri UV-Vis, Penerbit Mecphiso Grafika, Surabaya.

Musaddad, D. dan Hartuti, N., 2003, Produk Olahan Tomat, Seri Agribisnis Penebar Swadaya, Jakarta.

Sastrohamidjojo, H., 1985, Kromatografi, Liberty,Yogyakart a.

Suprapti, A., 2000, Saus Tomat dan Cabe Giling, (http://www-pikiranrakyat.com, diakses 6 Juni 2012.

Syah, et al., 2005, Manfaat dan Bahaya Bahan Tambahan Pangan, Himpunan Alumni Fakultas Teknologi Pertanian IPB, Bogor.

Trestiati dan Mela, 2003, Analisis Rhodamin B Pada Makanan dan Minuman Jajanan Anak SD (Studi Kasus: Sekolah Dasar di Kecamatan Margaasih Kabupaten Bandung), Tesis Pascasarjana Fakultas Kesehatan Bandung. 